\title{
Dinâmica da pastagem e desempenho de novilhos em pastagem de capim- tanzânia sob diferentes ofertas de forragem ${ }^{1}$
}

\author{
1 Parte da tese de Doutorado do primeiro autor. \\ ${ }^{2}$ Departamento de Zootecnia da União Pioneira de Integração Social, Brasília, DF. \\ ${ }^{3}$ Departamento de Zootecnia da Universidade Federal de Viçosa, Viçosa, MG. \\ ${ }^{4}$ Departamento de Zootecnia da Universidade Estadual de Maringá, Maringá, PR.
}

Marco Aurélio Alves de Freitas Barbosa ${ }^{2}$, Domicio do Nascimento Júnior ${ }^{3}$, Ulysses Cecato ${ }^{4}$

RESUMO - Um experimento foi realizado com o objetivo de estudar a dinâmica de produção da pastagem e o desempenho animal em pastagem de capim-tanzânia (Panicum maximum Jacq. cv. Tanzânia) sob lotação contínua, com taxa de lotação variável e quatro ofertas de forragem $(3,7,11$ e $15 \%$ do PV). Foram utilizados novilhos mestiços Nelore x Charolês com média de 18 meses de idade e $350 \mathrm{~kg}$ de PV. O delineamento experimental adotado foi em blocos casualizados, com três repetições. O intervalo de 7 a $11 \%$ de oferta de forragem consiste na faixa em que o capim-tanzânia deve ser manejado com mínima aplicação de fertilizantes (30 kg/ha/ano de N) para obtenção de alto ganho médio diário (GMD), sem afetar demasiadamente o ganho por hectare (G/ha). Nesta condição, a pastagem apresenta-se com $1.528 \mathrm{~kg} / \mathrm{ha}$ de MSLV; $56 \mathrm{~cm}$ de altura; $97 \%$ de cobertura de solo; $62 \mathrm{~kg} / \mathrm{ha} / \mathrm{dia}$ de taxa de crescimento de MSLV e 34\% de lâminas verdes na MS total, resultando em GMD de 0,5 kg/dia e G/ha de $126 \mathrm{~kg}$.

Palavras-chave: ganho médio diário, ganho por hectare, lotação contínua

\section{Pasture dynamic and performance of steers in Panicum maximum Jacq. cv. Tanzânia under different forage allowances}

\begin{abstract}
This experiment was carried out from March to August 2000, to study the dry matter yield dynamic and performance of steers grazing Tanzania grass (Panicum maximum Jacq. cv. Tanzânia), under continuous stocking with variable stocking rate, and four forage allowances $(3,7,11$, and $15 \% \mathrm{BW})$. Crossbred Nelore $\mathrm{x}$ Charolais steers, averaging 18 months and $350 \mathrm{~kg} \mathrm{BW}$, were used. A randomized block design, with three replicates, was used. When tanzaniagrass was managed in the 7 to $11 \%$ interval of forage allowance, the fertilizer input was minimal $(30 \mathrm{~kg} / \mathrm{ha} / \mathrm{yr} \mathrm{N})$, and high average daily gain (ADG) was obtained, with no effect on the gain/ha (G/ha). Under this condition, pasture showed 1,528 $\mathrm{kg} / \mathrm{ha}$ green leaf lamina dry matter (GLLDM); $56 \mathrm{~cm}$ of stubble height; 97\% soil cover; $62 \mathrm{~kg} / \mathrm{ha} /$ day of GLLDM accumulation rate; and 34\% green leaf lamina in the total dry matter, with ADG of $0.5 \mathrm{~kg} /$ day and $126 \mathrm{~kg}$ of $\mathrm{G} / \mathrm{ha}$.
\end{abstract}

Key Words: average daily gain, continuous stocking, gain per hectare

\section{Introdução}

O manejo de pastagens tem como principal finalidade a otimização da produção forrageira e da eficiência de uso da forragem produzida visando ao desempenho animal e à produção animal por hectare. A perenidade e a estabilidade da pastagem dependem de práticas de manejo diversas, entre as quais se destaca a adoção de oferta de forragem compatível com a capacidade de suporte da pastagem. Taxas de lotação muita acima ou muito abaixo da capacidade de suporte resultam em subestimativas do desempenho animal e da produção animal por área (Gomide \& Gomide, 2001).

Alguns cultivares de Panicum maximum Jacq. estão entre as principais forrageiras cultivadas no Brasil. Os dados sobre a área ocupada pelos cultivares da espécie no país nem sempre são precisos, mas indicam serem bastante difundidos no território nacional. Pode-se estimar que a espécie já ocupou área superior a 6 milhões de hectares no Brasil (em sua maioria com capim-colonião). Provavelmente, hoje, essa área é menor, pois problemas de manejo e de fertilidade do solo têm prejudicado essas pastagens (Aronovich, 1995).

Entre os cultivares da espécie Panicum maximum, o plantio de capim-tanzânia tem sido bastante estimulado (Aronovich, 1995) por suas excelentes características agronômicas e de consumo pelos animais. Brâncio et al. (2002) avaliaram três cultivares de $P$. maximum e observaram que, de modo geral, o capim-tanzânia apresenta os melhores valores nutricionais. 
Em pastagens de capim-tanzânia, os resultados de GMD têm variado de 0,6 a 1,15 kg/dia e os G/ha, de 250 a $1.304 \mathrm{~kg} / \mathrm{ha}$ (Euclides, 1995; Watfe, 1999; Almeida Jr., 2003; Rodrigues, 2003).

A altura da pastagem tem sido utilizada como critério de manejo, principalmente em pastagens de azevém perene e trevo branco na Inglaterra, Nova Zelândia e França. Nesses países, muitas pesquisas têm sido conduzidas visando estimar o efeito da utilização de diferentes alturas da pastagem na produção de forragem e, principalmente, no desempenho animal. Segundo Forbes (1988) e Brâncio et al. (2002), existe correlação alta e positiva do consumo de forragem de animais em pastejo com a altura da pastagem.

Em estudo realizado em pastagens de capim-tanzânia sob lotação contínua, Rêgo et al. (2001) e Cano (2002) sugeriram a manutenção da altura da pastagem entre 40 e $60 \mathrm{~cm}$. Hodgson \& da Silva (2002) concluíram, com base nos resultados de vários experimentos com Panicum maximum, que a intensidade tem menos importância que a freqüência de desfolha no crescimento e na utilização da pastagem, com indicações de que as pastagens devem ser desfolhadas quando atingirem valores próximos a $95 \%$ de interceptação da luz incidente (equivalente à massa de forragem pré-pastejo de $5.000 \mathrm{~kg} /$ ha ou à altura de $80-90 \mathrm{~cm}$ ) e que o resíduo pós-pastejo deveria ser de 2.000 a $2.500 \mathrm{~kg} / \mathrm{ha}$ de MS verde (equivalente à altura de resíduo de $30 \mathrm{~cm}$ ), reduzindo a altura deste resíduo para $15-20 \mathrm{~cm}$ no outono, objetivando controlar o excessivo crescimento de colmos.

Importantes resultados têm sido divulgados por Santos (1997) e Santos et al. (1999), que estudaram algumas características agronômicas do cultivar Tanzânia, a fim de estabelecer suas técnicas de manejo. No entanto, os trabalhos foram conduzidos em lotação rotacionada e, na maioria das pastagens utilizadas no Brasil, o sistema adotado é o de lotação contínua, sendo encontradas poucas informações sobre a utilização de oferta de forragem como critério de manejo.

Objetivou-se com este trabalho gerar informações sobre o manejo de pastagens de capim-tanzânia sob lotação contínua com taxa de lotação variável.

\section{Material e Métodos}

O experimento foi realizado na propriedade do Sr. Raulino Westphal, Fazenda 46, latitude $23^{\circ} 23^{\prime}$ e longitude $52^{\circ} 56^{\prime}$, localizada no município Cidade Gaúcha, Paraná, a 550 m de altitude. Segundo classificação de Köppen, o clima da região é Cfa (subtropical úmido com verão quente) com precipitação total média anual (histórica) de $1.300 \mathrm{~mm}$. As informações de precipitação pluviométrica e tempe- raturas mínimas e máximas para o período de agosto de 1999 a agosto de 2000 encontram-se nas Figuras 1 e 2, respectivamente.

O solo da área experimental é do tipo Podzólico Vermelho-Amarelo e, segundo análise, apresentou os seguintes resultados: $\mathrm{pH}$ em água $=5,0 ; \mathrm{Ca}=1,4 \mathrm{cmolc} /$ $\mathrm{dm}^{3} ; \mathrm{Mg}=0,4 \mathrm{cmolc} / \mathrm{dm}^{3} ; \mathrm{Al}=0,0 \mathrm{cmolc} / \mathrm{dm}^{3} ; \mathrm{H}+\mathrm{Al}=$ $1,3 \mathrm{cmolc} / \mathrm{dm}^{3} ; \mathrm{P}=3,1 \mathrm{mg} / \mathrm{dm}^{3} ; \mathrm{K}=105,0 \mathrm{mg} / \mathrm{dm}^{3}$; e saturação por bases $=61,4 \%$.

A área experimental foi desmatada em 1952, quando foi implantada a cultura de café e, a seguir, a de capimcolonião (1960). Após sua degradação total (1993), foi invadida por grama-batatais (Paspalum notatum) e, posteriormente, cultivada com milho e feijão. Em 21/11/ 1993, a área foi semeada com capim-tanzânia (Panicum maximum Jacq. cv. Tanzânia), sendo utilizada até o período deste experimento em lotação contínua por bovinos mestiços Nelore x Charolês.

Em dezembro de 1999, foram retirados os animais da área e, em 18/01/2000, foram aplicados $30 \mathrm{~kg}$ de N/ha, em forma de uréia.

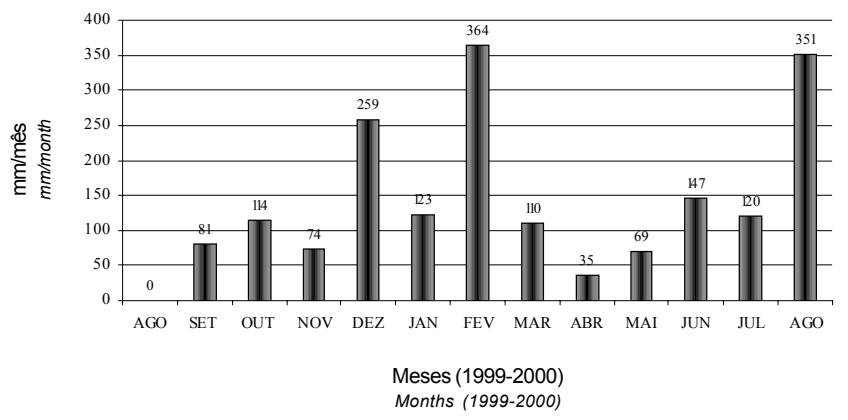

Figura 1 - Precipitação pluviométrica no período de agosto de 1999 a agosto de 2000. Fonte: USACIGA - Cidade Gaúcha - PR.

Figure 1 - Pluviometric precipitation collected from August 1999 to August 2000. Source: USACIGA - Cidade Gaúcha - PR.

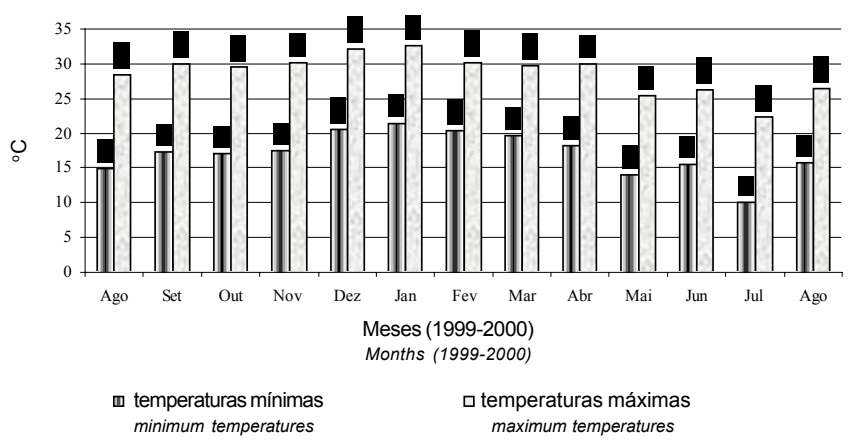

Figura 2 - Temperaturas mínimas e máximas coletadas no período de agosto de 1999 a agosto de 2000 . Fonte: SIMEPAR - Estação de Paranavaí - PR.

Figure 2 - Minimum and maximum temperature collected from August 1999 to August 2000. Source: SIMEPAR - Estação de Paranavaí-PR. 
O experimento foi implantado em uma área ( $15 \mathrm{ha}$ ), com relevo suave-ondulado, dividida em 12 piquetes com 0,5 ; 1,$0 ; 1,5$ e 2,0 ha para as ofertas de forragem (OF) de $3 ; 7 ; 11$ e $15 \%$ do PV (Almeida, 1997), respectivamente, todas com três repetições, em blocos casualizados.

Foram avaliadas em sistema de lotação contínua quatro ofertas de forragem pretendidas (OF), 3, 7, 11 e 15\% do PV, definidas como $\mathrm{kg}$ de MS de lâminas verdes totais (lâminas foliares verdes de capim-tanzânia + lâminas foliares verdes de outras espécies com potencial de pastejo) por $100 \mathrm{~kg}$ de PV/dia em pastagem de capim-tanzânia (Panicum maximum Jacq. cv. Tanzânia).

Utilizaram-se novilhos mestiços Nelore x Charolês com média de 18 meses de idade e $350 \mathrm{~kg}$ de PV. Adotou-se a técnica put-and-take (Mott \& Lucas, 1952) para o ajuste da taxa de lotação às OF, utilizando-se dois animais por tratamento como testers e grazers na quantidade necessária à manutenção das ofertas pretendidas. Todos os animais foram marcados com ferro quente e identificados com brincos plásticos numerados. O período de pastejo compreendeu os meses de março a agosto de 2000.

Os animais foram pesados no início do período de pastejo e a cada 28 dias, para controle da OF, mensuração do ganho de peso vivo (GPV) e do ganho médio diário(GMD). Após 12 horas de jejum, por ocasião das pesagens, foram feitos os ajustes das taxas de lotação às OF pretendidas.

Foram realizadas vacinações contra doenças da região e aplicações de vermífugos de acordo com as recomendações de médicos veterinários, fazendo-se o controle permanente de ectoparasitas. Foram fornecidas mistura mineral e água à vontade durante todo o período experimental. Não houve acesso à sombra.

As estimativas de resíduo de MS de lâminas verdes na pastagem foram realizadas em intervalos de 28 dias ou menos, quando necessário (reajuste), utilizando-se o método do rendimento comparativo (Haydock \& Shaw, 1975), pelo qual são somadas em cada avaliação e em cada piquete cinco amostras de corte e 20 estimativas visuais realizadas por seis observadores treinados.

Tanto nas amostras de corte como nas visuais, determinou-se a altura média da pastagem utilizando-se régua milimetrada. Os cortes foram feitos rente ao solo utilizando-se quadros de 0,5 x 0,5 m. Após o corte, as amostras de plantas foram levadas ao laboratório para a separação e a devida pesagem dos componentes lâminas verdes, colmos + bainha, material senescente e outras espécies. Subamostras foram secas em estufa de circulação forçada a $80^{\circ} \mathrm{C}$ por 48 horas para determinação dos teores de MS.

A determinação da cobertura de solo foi feita em áreas destinadas a amostras de corte e visuais, por meio da estimativa visual dos percentuais de cobertura da parte aérea das plantas em relação à área do solo dentro do quadrado de amostragem de matéria seca.

Para o cálculo da taxa de crescimento de lâminas verdes, foram utilizadas duas gaiolas de exclusão por piquete. As amostras foram coletadas da mesma forma que as anteriores e sofreram os mesmos tratamentos.

O delineamento experimental adotado para a avaliação do ganho de peso dos animais foi em blocos casualizados, com quatro tratamentos (quatro ofertas de forragem: 3, 7, 11, e $15 \%$ do PV) e três repetições. O efeito da OF no desempenho animal foi avaliado mediante análise de regressão.

O delineamento experimental adotado na avaliação da dinâmica da pastagem (altura das plantas, taxa de crescimento, massa de forragem, composição botânica e cobertura de solo) foi o mesmo descrito anteriormente. De acordo com os resultados do teste $\mathrm{F}$ nesta análise e, dependendo do fator, foram aplicados procedimentos para análise de regressão.

\section{Resultados e Discussão}

Conforme representado na Figura 3, o resíduo de MS (RMS) apresentou resposta linear positiva em função das OF, de modo que o valor mínimo foi de $1.959,48 \mathrm{~kg} / \mathrm{ha} \mathrm{de}$ MS e o máximo, de $5.574,3 \mathrm{~kg}$ de $\mathrm{MS} / \mathrm{ha}$. Os resíduos de colmo+bainha (RMSCOL), de lâminas verdes (RMSLV), material morto (RMSMM) e de outras espécies (RMSOUT) apresentaram resposta curvilinear em função das OF. Os RMSCOL e RMSMM resultaram em pontos de máximos e mínimos, respectivamente, fora do intervalo estudado (OF de 3 a $15 \%$ do PV), enquanto RSMLV e RMSOUT apresentaram pontos de máximo de 13,92 e 13,33\% do PV, respectivamente.

Os resultados referentes ao RMS demonstram como podem ser falhas as estimativas para o ajuste da taxa de lotação das pastagens quando se considera esta variável. O RMS de $1.958 \mathrm{~kg}$ de MS/ha seria suficiente para proporcionar desempenhos elevados em bovinos sob pastejo, pois foi superior ao estabelecido por Moore (1980). No entanto, este valor seria mais aplicado às gramíneas de clima temperado, pois, em gramíneas tropicais, de hábito de crescimento cespitoso, quando se utiliza o RMSLV, observa-se valor mais condizente ao que realmente o animal procura em pastejo.

$\mathrm{Na}$ OF de 3\% do PV, o RMSLV foi equivalente a $973 \mathrm{~kg}$ de MS/ha e participou com $48 \%$ da MS total disponível, enquanto, na OF de $11 \%$ do PV, foi de $1.528 \mathrm{~kg}$ de MS/ha de lâminas verdes, apesar de participar com aproximadamente $34 \%$ da MS total. 


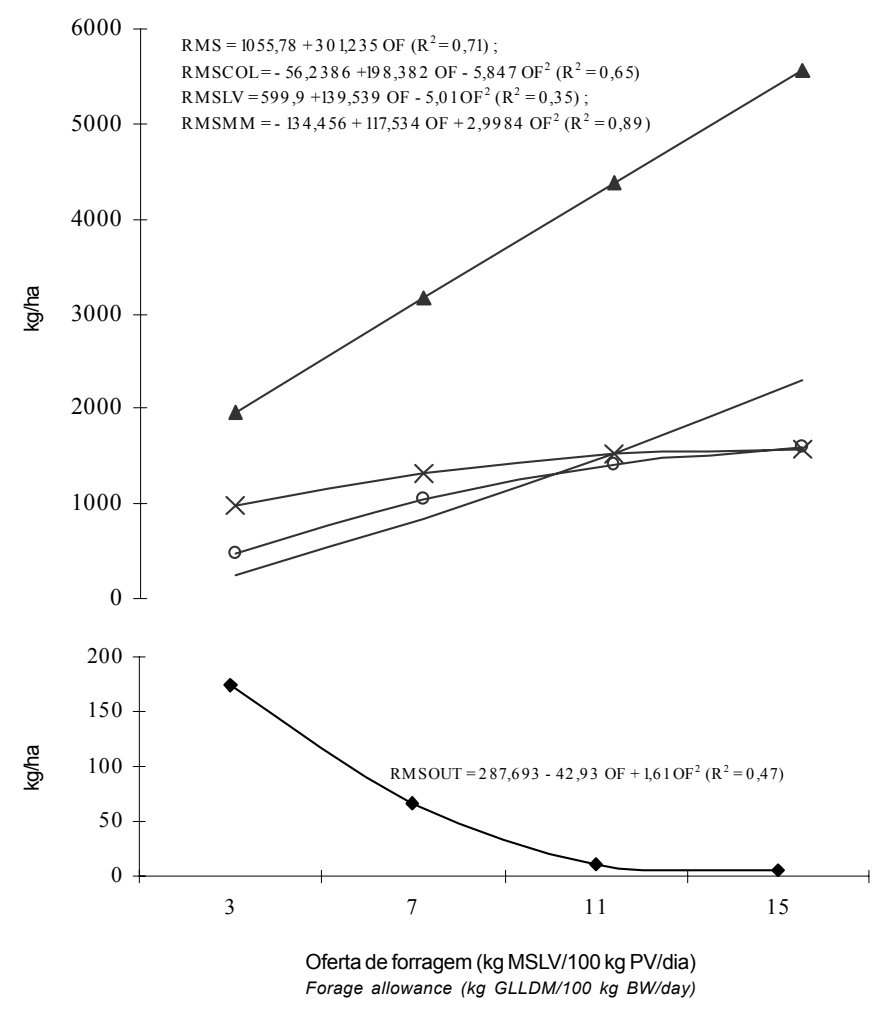

Figura 3 - Resíduos de matéria seca (RMS - $\mathbf{A}-$ ), de colmo+bainha (RMSCOL —o-), de lâminas verdes (RMSLV - x-), de material morto (RMSMM -) e de outras espécies (RMSOUT $-\downarrow-$ ) para as ofertas de forragem de 3, 7, 11 e $15 \mathrm{~kg}$ de MSLV/100 kg de $\mathrm{PV} /$ dia durante o período de crescimento de março a agosto de 2000.

Figure 3 - Total herbage mass (RMS - $\mathbf{-}$ ), stem + sheath mass (RMSCOL-o—), green leaflamina mass (RMSLV—x-), dead material (RMSMM -) and other species (RMSOUT $\longrightarrow-$ ) as affected by different forage allowances $(3 ; 7 ; 11$; and 15 $\mathrm{kg}$ GLLDM/100 kg LW/day), from March to August 2000.

Segundo Gomide \& Gomide (2001), a relevância da relação folha/colmo varia conforme a espécie forrageira, sendo menor naquelas com colmo tenro e menos lignificado, o que justifica a melhor correlação dos ganhos diários de peso vivo com a disponibilidade de MS verde total que com a de MS verde de folhas, em pastagens de Brachiaria decumbens e Brachiaria brizantha (Euclides et al., 1993).

Antecipa-se, no entanto, que a preensão da forragem em pastagens de capins jaraguá, setária e elefante anão 'Mott' seja mais dependente das relações folha/colmo, haja vista a maior proporção de esclerênquima e vasos lenhosos lignificados nos colmos em relação às folhas nessas gramíneas (Queiroz et al., 2000a,b).

Sabe-se que bovinos em pastejo preferem folhas a colmos e materiais senescentes (Carvalho et al., 2001). Portanto, trabalhos realizados com gramíneas forrageiras tropicais de hábito de crescimento cespitoso que utilizam o RMS como única fonte de controle de OF podem induzir a erros, pois pastagens com a mesma quantidade total de MS disponível podem conter diferentes quantidades de lâminas verdes.

O RMSCOL, como esperado, aumentou em função das $\mathrm{OF}$, pois, à medida que aumenta a quantidade de forragem disponível para o animal, começa a sobrar forragem, resultando em maior altura da pastagem e em maior quantidade de material morto, como conseqüência do alongamento dos entrenós e das sobras de folhas, as quais provocam sombreamento das folhas mais velhas e senescência. $\mathrm{O}$ acréscimo da OF resultou em aumentos da altura da pastagem e da cobertura do solo (Figura 4). O RMSLV apresentou resposta curvilinear em função da OF, com ponto de máximo em $13,92 \%$ do $\mathrm{PV}$, enquanto o RMSMM aumentou até $15 \%$ de PV, como resultado da sobra de forragem.

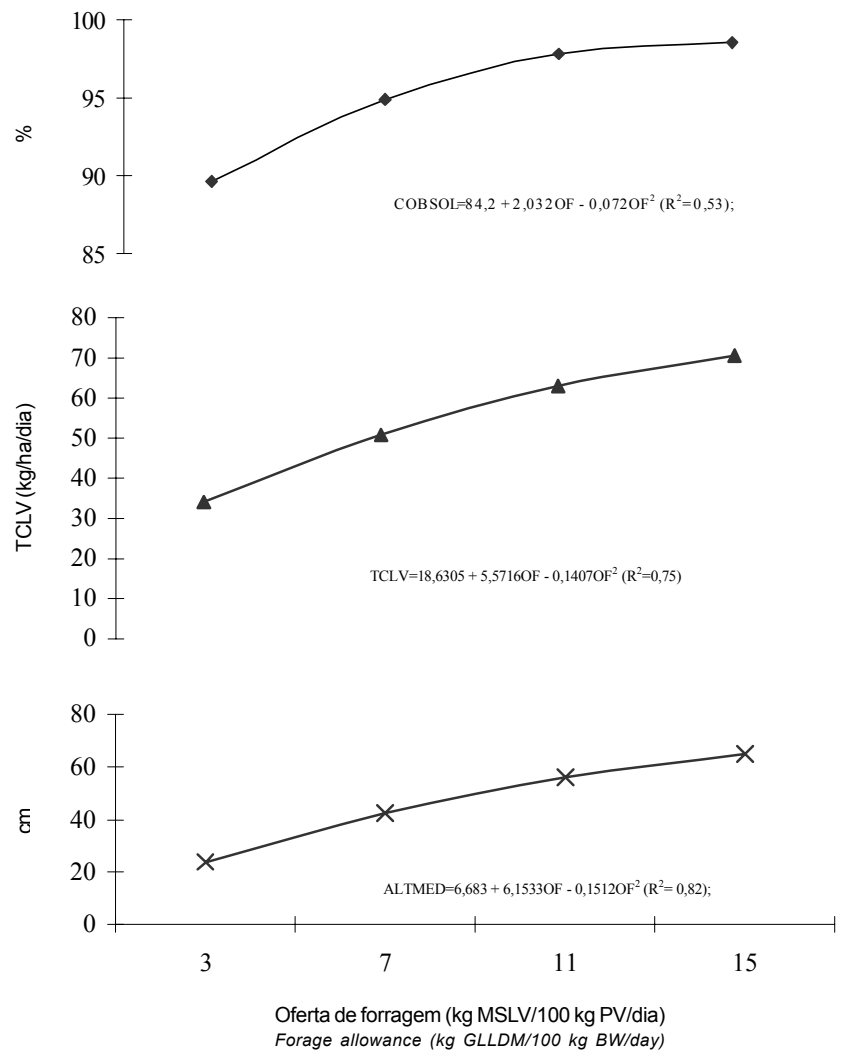

Figura 4 - Percentual de cobertura do solo (COBSOL $-\downarrow-$ ), taxa de crescimento de lâminas verdes (TCLV - $\mathbf{\Delta}-$ ) e altura da pastagem (ALTMED - $x-$ ) para as ofertas de forragem de 3, 7, 11 e $15 \mathrm{~kg}$ de MSLV/100 kg de $\mathrm{PV} /$ dia durante o período de março a agosto de 2000 .

Figure 4 - Soil cover percentage (COBSOL $-\downarrow-)$, green leaf lamina accumulation rate (TCLV- - -) and sward height (ALTMED $-x-)$ as affected by different forage allowances (3; $7 ; 11$; and $15 \mathrm{~kg}$ GLLDM/100 kg LW/day), from March to August 2000. 
O acúmulo de material morto é conseqüência de vários fatores como a diminuição da quantidade e da qualidade de luz que atravessa o dossel. $\mathrm{Na}$ OF de $3 \%$, maior quantidade de luz atinge a base da planta, enquanto, nas maiores OF, ocorre o inverso, como conseqüência da maior altura das plantas e da maior quantidade de folhas cobrindo o solo. Provavelmente, com OF de $11 \%$, a pastagem tenha atingido ou ficado próximo de seu IAF máximo, visto que o aumento de lâminas verdes foi inexpressivo a partir desse ponto.

Quando a quantidade de lâminas verdes foi expressa em porcentagem (Figura 5), decresceu da OF de 11 para a de $15 \%$ e a quantidade de material morto foi sempre crescente. A taxa de crescimento de lâminas verdes também apresenta resposta curvilinear conforme o aumento da OF, porém, com aumentos até $15 \%$ de OF. Outro motivo para o aumento do RMSMM seria a sobra de forragem nas maiores OF.

Os resultados observados refletem a resposta da pastagem às $\mathrm{OF}$, de modo que, nas menores $\mathrm{OF}$, ao contrário da OF de $15 \%$, houve maior participação de lâminas na produção total e menor participação de colmos + bainhas e material morto. Esses resultados estão de acordo com os relatos de Chapman \& Lemaire (1993) de que a planta forrageira modifica sua morfologia conforme a intensidade e a freqüência de desfolha.

A participação de outras espécies na composição botânica da pastagem também foi influenciada pela OF.

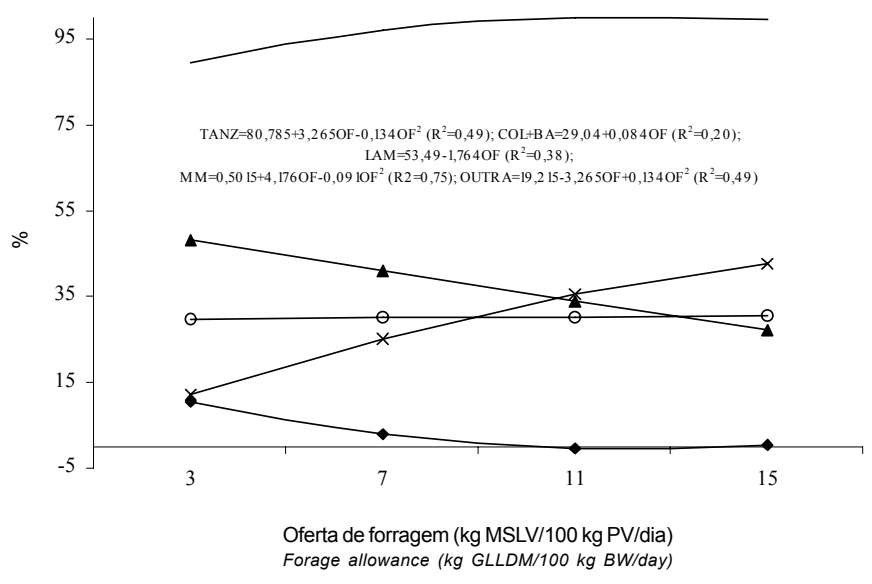

Figura 5 - Percentual de capim-tanzânia (TANZ -), de colmo+bainha ( $\mathrm{COL}+\mathrm{BA}-\mathrm{O}-)$, de lâminas verdes (LAM - - - ), de material morto (MM - $x-$ ) e de outras espécies (OUTRA $-\longrightarrow$ ) para quatro ofertas de forragem ( $\mathrm{kg} \mathrm{MSLV/100} \mathrm{kg} \mathrm{PV/dia)} \mathrm{no} \mathrm{período} \mathrm{de}$ março a agosto de 2000 .

Figure 5 - Percentages of tanzaniagrass (TANZ -), stem + sheath ( $C O L+B A-O-)$, green leaflamina ( $L A M-\mathbf{\Lambda}-)$, dead material (MM- - -) and other species (OUTRA - -) as affected by four forage allowances ( $\mathrm{kg}$ GLLDM/100 $\mathrm{kg} L W /$ day), from March to August 2000.
Quando a OF era baixa, maior quantidade de outras espécies compunham a pastagem (Brachiaria brizantha, B. decumbens, B. humidicola e Paspalum notatum, entre outras espécies sem potencial para pastejo), mas, à medida que se elevou a OF, o capim-tanzânia tornou-se a espécie predominante ( $100 \%$, na OF de $13,18 \%$ do PV).

Estes resultados podem ser atribuídos à maior altura do capim-tanzânia nas maiores OF, o qual sombreava as outras espécies. No entanto, nas menores OF, como houve maior intensidade de desfolha e menor cobertura do solo, ocorreu maior participação de outras espécies. $\mathrm{O}$ animal em pastejo consome a espécie e/ou a parte da planta mais preferida, beneficiando as plantas indesejáveis à medida que não provoca a ação da desfolha. Assim, nas menores OF, o capim-tanzânia era pastejado preferencialmente, enquanto outras espécies podiam multiplicar-se por não sofrerem ação da desfolhação. Isso comprova que OF muito baixas em pastagens de capim-tanzânia podem conduzi-las à degradação. Ao final do período de avaliação (agosto de 2000), um dos três piquetes que compunham o tratamento de OF de $3 \%$ do PV apresentou sinais de degradação de plantas.

Os resultados de GMDV e $\mathrm{G} / \mathrm{haV}$ descritos na Figura 6 são referentes a um período de engorda de 70 dias, que teve início em março de 2000. O GMDG apresentou ponto de máximo na OF de $9,2 \%$ do $\mathrm{PV}$, enquanto os pontos de máximo dos GMDV e GMDI ocorreram na OF de $10,35 \%$ do PV. Os pontos de máximo do $\mathrm{G} / \mathrm{haG}$ e do $\mathrm{G} / \mathrm{haI}$, no entanto, foram observados nas OF de 6,27 e $10,62 \%$ do $\mathrm{PV}$, ao passo que o $\mathrm{G} / \mathrm{haV}$ apresentou ponto de máximo fora das OF avaliadas.

Estes resultados estão de acordo com os relatados por Almeida (1997), que observou que valores em torno de $10 \%$ do PV de OF de lâminas verdes proporcionaram os melhores resultados de GMD. Todavia, o G/haV encontrado neste experimento pode conduzir à hipótese de que menor OF poderia porporcionar maiores retornos econômicos, em virtude dos maiores ganhos por unidade de área. Entretanto, os valores de GMDI e G/haI indicam instabilidade dos resultados obtidos na OF de $3 \%$ do $\mathrm{PV}$, pois o animal mantém pequenos ganhos por pouco tempo e logo depois começa a perder peso. Adicionalmente, a pastagem começa a apresentar sinais de degradação de plantas, como resultado de seu porte reduzido, do aumento da participação de outras espécies, da diminuição da cobertura do solo e da menor taxa de crescimento de lâminas verdes, que, em conjunto, contribuem para menor RMSLV disponível, o que impede a obtenção de valores satisfatórios de desempenho animal. 

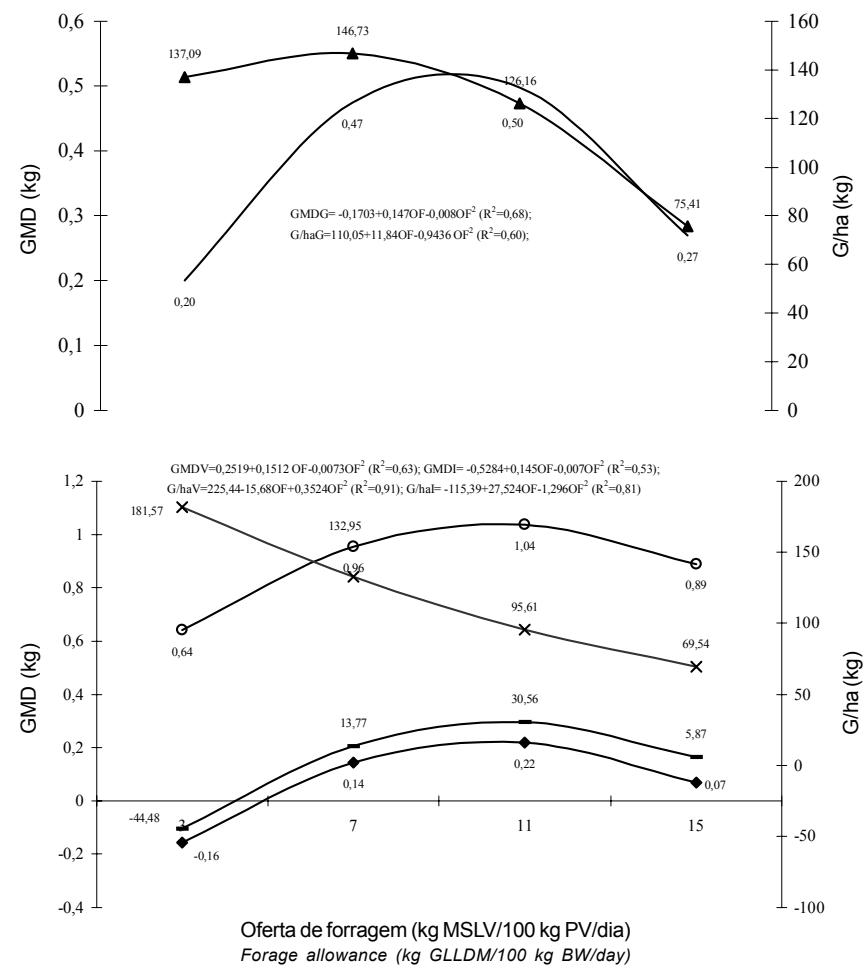

Figura 6 - Ganho médio diário geral (GMDG -), ganho por hectare geral ( $\mathrm{G} / \mathrm{haG}-\mathbf{\Delta}-)$, ganho médio diário no verão (GMDV -o-), ganho por hectare no verão (G/haV - x--), ganho médio diário no inverno (GMDI - - ) e ganho por hectare no inverno (G/hal - - -), em pastagens de capim-tanzânia sob quatro ofertas de forragem ( $\mathrm{kg} \mathrm{MSLV/100} \mathrm{kg} \mathrm{PV/dia)} \mathrm{no}$ período de março a agosto de 2000.

Figure 6 - Overall average daily gain (GMDG -), general gain/ha (G/haG $\mathbf{-} \boldsymbol{\Delta}-$ ), average daily gain in the summer (GMDV - o-), gain/ha in the summer ( $G / h a V-x-)$, average daily gain in the winter (GMDI - -) and gain/ha in the winter (G/hal _ - -) in tanzaniagrass pasture, under four forage allowances (kg MSLV/100 kg LW/day), from March to August 2000.

Estes maiores valores de $\mathrm{G} / \mathrm{haV}$ observados na OF de $3 \%$ do $\mathrm{PV}$ podem ser atribuídos principalmente à maior quantidade de animais necessários para se atingir a referida OF. Deve-se ressaltar ainda que animais em terminação neste sistema levam muito mais tempo para atingir o peso de abate, sem considerar a qualidade da carcaça de um animal terminado ganhando em torno de $1,0 \mathrm{~kg} / \mathrm{dia}$ $(10,35 \%$ do PV) e outro $0,6 \mathrm{~kg} / \mathrm{dia}$ ( $3 \%$ do PV). Cabe salientar que parte do ganho de peso dos animais mantidos na OF de $3 \%$ do PV foi perdida durante o inverno e que os animais mantidos na OF de $11 \%$ continuaram a ganhar peso nesse período.

O melhor desempenho dos animais na OF de 10,35\% pode ser explicado pelo melhor equilíbrio entre boa disponibilidade de lâminas verdes, colmo+bainha, altura da pastagem e quantidade de material morto.
Aparentemente, no intervalo de 7 a $11 \%$ de OF, encontra-se a faixa em que o capim-tanzânia deve ser manejado, com mínima aplicação de fertilizantes (30 kg/ha/ano de N), para a obtenção de altos GMD sem afetar demasiadamente o $\mathrm{G} / \mathrm{ha}$. Outro fator a ser considerado a longo prazo é a sustentabilidade do ecossistema de pastagem, que está intimamente ligada ao material residual remanescente na pastagem, pois, quando manejadas em superpastejo, semelhante a 3\% de OF, tendem a apresentar degradação de plantas.

\section{Conclusões}

Em pastagens de capim-tanzânia sob pastejo em lotação contínua e a taxas de lotação variável, a oferta de forragem mais condizente para a associação entre ganho médio diário, ganho por hectare e dinâmica da pastagem encontra-se na faixa de oferta de forragem de 7 a $11 \%$ do peso vivo.

\section{Agradecimento}

À família Westphal, por conceder os animais experimentais, a área de pastagem e a infra-estrutura necessária à condução do experimento.

À Cerca Animal Amazonas, pelo fornecimento dos materiais utilizados na confecção das cercas eletrificadas.

À Universidade Estadual de Maringá, pelo apoio com estagiários e alojamento.

\section{Literatura Citada}

ALMEIDA, E.X. Oferta de forragem de capim elefante anão (Pennisetum purpureum Schum. cv. Mott), dinâmica da pastagem e sua relação com o rendimento animal no Alto Vale do Itajaí, Santa Catarina. Porto Alegre: Universidade Federal de Rio Grande do Sul, 1997. 112p. Tese (Doutorado em Zootecnia) - Universidade Federal de Rio Grande do Sul, 1997.

ALMEIDA JR., J. Produção, qualidade de forragem, desempenho animal e avaliação econômica de capim-tanzânia com diferentes níveis de nitrogênio. Maringá: Universidade Estadual de Maringá, 2003. 59p. Dissertação (Mestrado em Zootecnia) - Universidade Estadual de Maringá, 2003.

ARONOVICH, S.O. capim colonião e outros cultivares de Panicum maximum (Jacq.): introdução e evolução do uso no Brasil. In: SIMPÓSIO SOBRE MANEJO DA PASTAGEM, 12., 1995, Piracicaba. Anais... Piracicaba: Fundação de Estudos Agrários Luiz de Queiroz, 1995. p.1-20.

BIRCHAM, J.; HODGSON, J. The influence of sward condition on rates of herbage growth and senescence in mixed swards under continuous stocking management. Grass and Forage Science, v.38, p.323-331, 1983.

BRÂNCIO, P.A.; NASCIMENTO JR., D.; EUCLIDES, V.P.B. et al. Avaliação de três cultivares de Panicum maximum Jacq. sob pastejo. Composição química e digestibilidade da forragem. Revista Brasileira de Zootecnia, v.31, n.4, p.1605-1613, 2002. 
CANO, C.C.P.; CECATO, U.; CANTO, M.W. et al. Produção de forragem do capim-tanzânia (Panicum maximum Jacq. cv. Tanzânia-1) pastejado em diferentes alturas. Revista Brasileira de Zootecnia, v.33, n.6, p.1949-1958, 2004 (supl. 2).

CARVALHO, P.C.F.; RIBEIRO, H.M.N.; POLI, C.H.E.C. et al. Importância da estrutura da pastagem na ingestão e seleção de dietas pelo animal em pastejo. In: REUNIÃO ANUAL DA SOCIEDADE BRASILEIRA DE ZOOTECNIA, 38., 2001, Piracicaba. Anais... Piracicaba: Sociedade Brasileira de Zootecnia, 2001. p.853.

CHAPMAN, D.F.; LEMAIRE, G. Morfogenic and strutural determinants of regrowth after defoliaton. In: INTERNATIONAL GRASSLAND CONGRESS, 17., 1993, Rockhampton. Proceedings... Palmerston North: New Zealand Grassland Association, 1993. p.95-104.

EUCLIDES, V.B.P. Valor alimentício de espécies forrageiras do gênero Panicum. In: SIMPÓSIO SOBRE MANEJO DE PASTAGENS, 12., 1995, Piracicaba. Anais... Piracicaba: Fundação de Estudos Agrários "Luiz de Queiroz", 1995. p.245-273.

EUCLIDES, V.P.B.; ZIMMER, A.H.; OLIVEIRA, M.P. Evaluation of $B$. decumbens and $B$. brizantha under grazing. In: INTERNATIONAL GRASSLAND CONGRESS, 17., 1993, Rockhampton. Proceedings... Palmerston North: New Zealand Grassland Association, 1993. p.1997-1998.

FORBES, T.D.A. Researching the plant-animal interface: the investigation of ingestive behaviour in grazing animals. Journal of Animal Science, v.66, n.9, p.2369-2379, 1988.

GOMIDE, J.A.; GOMIDE, C.A.M. Utilização e manejo de pastagens. In: REUNIÃO ANUAL DA SOCIEDADE BRASILEIRA DE ZOOTECNIA, 2001, 38., Piracicaba. Anais... Piracicaba: Sociedade Brasileira de Zootecnia, 2001. (CD-ROM). Forragicultura. Semi 54.

HAYDOCK, K.P.; SHAW, N.H. The comparative yield method for estimating dry matter yield of pasture. Australian Journal of Experimental Agriculture and Animal husbandry, v.15, n.76, p.663-670, 1975

HODGSON, J.; DA SILVA, S.C. Options in tropical pasture management. In: REUNIÃO ANNUAL DA SOCIEDADE BRASILEIRA DE ZOOTECNIA, 39., 2002, Recife, Anais... Recife: Sociedade Brasileira de Zootecnia, 2002. p.180-202.

MOORE, J.E. Forage crops. In: HOVELAND, C.S. (Ed.) Crop quality, storage and utilization. Madison: ASA e CSSA, 1980. p.61-91.

MOTT, G.O.; LUCAS, H.L. The designs conduct, and interpretation of grazing trials on cultivated and improved pastures. In: INTERNATIONAL GRASSLAND CONGRESS, 6., 1952, Pennsylvania. Proceedings... Pennsylvania: State College Press, 1952. p.1380-1385.
QUEIROZ, D.S.; GOMIDE, J.A.; MARIA, J. Avaliação da folha e do colmo do topo e a base de perfilhos de três gramíneas forrageiras. 1 - Digestibilidade in vitro e composição química. Revista Brasileira de Zootecnia, v.29, n.1, p.53-60, 2000a.

QUEIROZ, D.S.; GOMIDE, J.A.; MARIA, J. Avaliação da folha e do colmo do topo e a base de perfilhos de três gramíneas forrageiras. 2 - Anatomia. Revista Brasileira de Zootecnia, v.29, n.1, p.61-68, 2000b.

RÊGO, F.; CECATO, U.; CANTO, M.W. et al. Estudo de características morfológicas e índice de área foliar do capimtanzânia (Panicum maximum Jacq. cv. Tanzânia 1) manejado em diferentes alturas, sob pastejo. In: REUNIÃO ANUAL DA SOCIEDADE BRASILEIRA DE ZOOTECNIA, 38., 2001, Piracicaba, Anais... Piracicaba:Sonopress, 2001. (CD-ROM) Forragicultura. Código 0302.

RODRIGUES, A.M. Desempenho animal e produção de massa de forragem em pastagem de capim-tanzânia (Panicum maximum Jacq. cv. Tanzânia-1) sob diferentes níveis de nitrogênio. Maringá: Universidade Estadual de Maringá, 2003. 24p. Monografia (Graduação em Zootecnia) - Universidade Estadual de Maringá, 2003.

SANTOS, P.M.; BALSALOBRE, M.A.A.; CORSI, M. Características morfogenéticas e taxa de acúmulo de forragem do capimMombaça submetido a três intervalos de pastejo. Revista Brasileira de Zootecnia, v.33, n.4, p.843-851, 2004.

SANTOS, P.M.; CORSI, M.; BALSALOBRE, M.A.A. Efeito da freqüência de pastejo e da época do ano sobre a produção e a qualidade em Panicum maximum cv. Tanzânia e Mombaça. Revista Brasileira de Zootecnia, v.28, n.2, p.244-249, 1999.

WATFE, E. Relação entre o desempenho por animal e características de uma pastagem de capim-tanzânia-1 manejada em diferentes alturas de pastagens. Maringá: Universidade Estadual de Maringá, 1999. 23p. Monografia (Graduação em Zootecnia) - Universidade Estadual de Maringá, 1999. 